\title{
PELATIHAN DESAIN PRODUK DAN IKLAN DIGITAL UNTUK KELURAHAN GAJAHMUNGKUR
}

\author{
Zahrotul Umami ${ }^{1}$, Muhammad Noor $\mathrm{H}^{2}$, Muh. Hasan Bashori M.A ${ }^{3}$ \\ 1,2,3 Program Studi Ilmu Komunikasi, Universitas Dian Nuswantoro \\ E-mail: ${ }^{1}$ zahrotul.umami@dsn.dinus.ac.id, ${ }^{2}$ muhammad.noor.hidayat@dsn.dinus.ac.id, \\ hasansbasori@gmail.com
}

\begin{abstract}
Abstrak
Desain produk menjadi sebuah hal yang penting bagi produsen jajanan pasar. Desain kemasan dan Iklan digital juga menjadi sarana penunjang dalam pemasaran produk jajanan pasar. Pengembangan kreativitas dan inovasi kemasan produk adalah kunci dalam meraih sukses untuk usaha yang dijalankan. Kemasan produk merupakan cara konsumen dalam menilai sebuah produk baik dari segi manfaat, estetika maupun kualitas produk tersebut. Desain produk yang unik, menjadi nilai tambah dalam pemasaran jajan pasar melalui iklan digital. Jajan pasar adalah potensi yang dimiliki Kelurahan Gajahmungkur, namun potensi tersebut tidak ditunjang dengan desain kemasan dan iklan digital dalam memperluas pemasaran. Melihat permasalahan tersebut maka Dosen ilmu komunikasi bekerja sama dengan Karang taruna Kelurahan Gajahmungkur membuat program pengabdian tentang pentingnya iklan digital yang ditunjang dengan desain kemasan yang unik untuk meningkatan pemasaran dari produk jajanan pasar yang ada di kelurahan Gajahmungkur. Kegiatan pengabdian tentang desain kemasan dan iklan digital diharapkan mampu membantu masyarakat kelurahan Gajahmungkur dalam memasarkan produk jajanan pasar sehingga dapat meningkatkan kesejahteraan masyarakat Kelurahan Gajahmungkur
\end{abstract}

Kata kunci: Desain Produk, Iklan Digital

\begin{abstract}
Product design become more important thing for traditional snack producers, especially jajan pasar, which is the term for traditional snack in the Semarang and Central Java Region. The design of packaging and digital advertising is also a supporting tool in marketing of jajan pasar. The development of creativity and product packaging innovation is the key to achieving success for the business being run. Product packaging is a way for consumers to judge a product both in the terms of benefits, aesthetics and quality of the product. The unique product design is an added value in marketing of jajan pasar through digital advertising. Jajan pasar are the potency of Gajahmungkur, but this potential is not supported by packaging design and digital advertising in expanding marketing. Seeing this problem, the communication science lecturer cooperated with Karang Taruna Gajahmungkur to create a public service program about the importance of digital advertising supported by a unique packaging design to increase the marketing of jajan pasar in the Gajahmungkur. Public service activities regarding packaging design and digital advertising are expected to be able to help the people of Gajahmungkur in marketing jajan pasar product so that they can improve the prosperity of Gajahmungkur communities
\end{abstract}

Keywords: Product Design, Digital Advertising 


\section{PENDAHULUAN}

Pengembangan kreativitas dalam inovasi kemasan produk merupakan salah satu kunci dalam meraih sukses untuk usaha yang dijalankan. Kemasan setiap produk merupakan cerminan awal konsumen dalam menilai sebuah produk baik dari segi manfaat, estetika maupun kualitas produk tersebut secara langsung maupun tidak langsung. Ragam visual berupa informasi brand name yang unik dan berbeda, tagline produk yang simpel dan berkesan, serta pemilihan audio yang tepat merupakan komposisi dalam menonjolkan citra pada sebuah produk [1]. Melalui penentuan komposisi tepat inilah yang dapat menjadikan sebuah produk memiliki bergaining position atau nilai tawar yang tinggi dimata konsumen atau masyarakat.

Industry makanan kemasan memiliki peranan yang sangat penting terutama dalam mendorong pemasaran produk makanan. Khususnya pada produk makanan berjenis snack atau makanan ringan, perancangan desain kemasan makanan ringan mempunyai tujuan yang lebih kompleks bukan hanya sekedar fungsinya sebagai tempat makanan atau pelindung makanan saja, akan tetapi sebagai fungsinya untuk memikat calon konsumen. Kemasan produk yang dahulu memakai bahan tipis kini lebih bervariasi menjadi lebih tebal, material yang digunakan lebih baik lagi dan desain kemasan pun dibuat semenarik mungkin agar bias menarik konsumen [2]. Kedua fungsi tersebut yang menjadi fungsi dasar kemasan. Usaha Kecil Menengah (UKM) masyarakat merupakan salah satu bagian pengembang ekonomi masyarakat daerah ditengah Masyarakat Ekonomi Asia (MEA) yang patut diberikan dukungan dan apresiasi dalam pengembangan usaha yang ada di Kampung Tematik Gajahmungkur. Baik dari segi kreatifitas desain kemasan dan iklan digital agar dapat bersaing diera digital 4.0 saat ini [3].

Tujuan pelatihan desain kemasan dan iklan digital ini adalah untuk memberikan pengetahuan bahwa kemasan merupakan hal yang penting sebagai salah satu komponen promosi dan pengembangan produk yang juga akan mempengaruhi proses periklanan baik cetak, elektronik maupun digital. Kebutuhan tentang desain kemasan produk makanan dan iklan digital agar dapat bersaing dengan produk lainnya sangat diperlukan, mengingat minimnya informasi bahwa Kampung Tematik Gajahmungkur merupakan sentra jajanan pasar. Minimnya informasi yang disebarkan tentang Kampung Temarih Gajahmungkur menjadi perhatian tersendiri, mengingat banyaknya usaha rumahan dan usaha kecil menengah (UKM) yang berkecimpung di industri makanan khususnya jajanan pasar.

Pentingnya desain kemasan produk dan iklan digital tak hanya sebagai alat wadah makanan dan juga alat promosi tetapi juga harus mampu menarik perhatian dan minat calon konsumen untuk membeli produk tersebut [4]. Hal ini disebabkan karena kurangnya bekal pemahaman akan desain kemasan produk dan iklan digital dan cara mempromosikan media ataupun kegiatan yang mampu memotivasi dan melatih kreativitas dalam membuat desain kemasan ataupun iklan digital produk makanan [5]. Untuk itu diperlukan semacam pelatihan yang dapat meningkatkan wawasan, pengetahuan, dan ketrampilan dalam membuat desain kemasan produk makanan dan iklan digital. Beberapa identifikasi masalah yang dapat diberikan solusi adalah :

1. Minimnya pemahaman dan wawasan akan kemasan produk makanan dan iklan digital di Kampung Tematik Gajahmungkur.

2. Terbatasnya kemampuan dan ketrampilan memanfaatkan material yang ada di lingkungan untuk dijadikan sarana pembuatan alat promosi.

Berdasarkan identifikasi masalah yang ada di atas, maka solusi yang akan ditawarkan pengusul adalah dengan membuat kegiatan pemberdayaan terhadap karang taruna kelurahan 
Gajahmungkur sebagai generasi muda yang turut serta aktif dalam pemberdayaan wilayahnya, yaitu mempromosikan produk yang dihasilkan oleh wilayah Kampung Tematik Gajahmungkur kepada khalayak. Dalam pelaksanaan, langkah-langkah yang akan dilakukan adalah sebagai berikut :

1. Pemahaman tentang cara berfikir kreatif, pentingnya media promosi, dan pengaplikasian media promosi juga cara menyebarkan media promosi yang sesuai. Pemaparan teknik dan pembaharuan dari segi wawasan terhadap desain kemasan produk makanan dan iklan digital melalui sosialisasi yang diberikan.

2. Peningkatan kemampuan ketrampilan pemuda karang taruna melalui simulasi dan praktik secara langsung. Pembahasan seputar ide, bentuk kemasan, warna, label, body copy, dan konten iklan produk. disampaikan secara komprehensif.

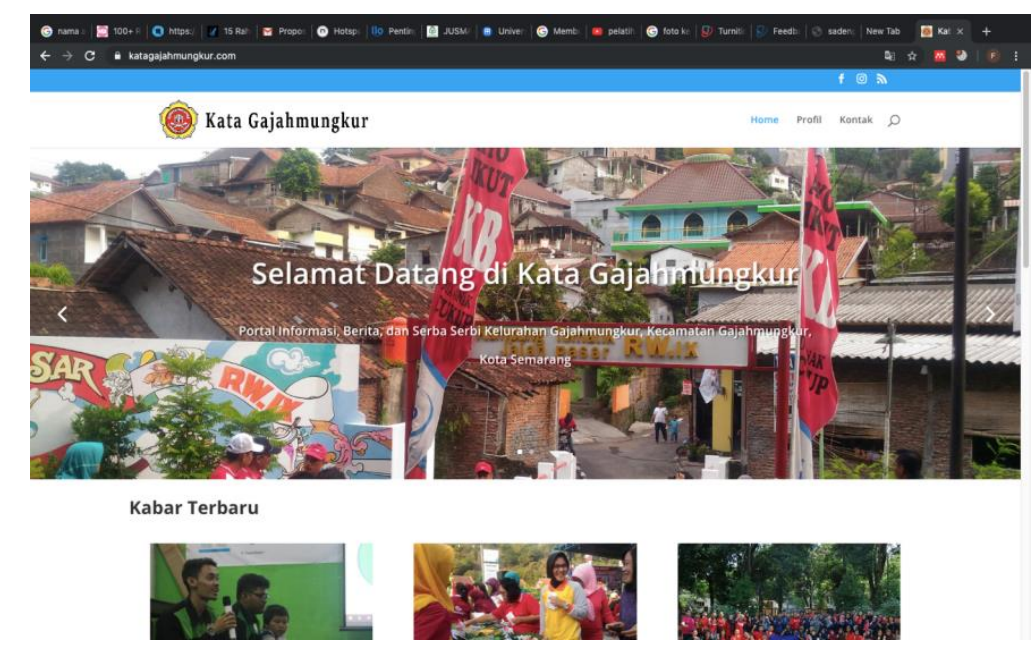

Gambar 1. Tampilan Website Karang Taruna Kelurahan Gajahmungkur

\section{METODE PELAKSANAAN}

Pelaksanaan kegiatan pengabdian ini menggunakan beberapa tahapan, yaitu :

1. Melakukan survey ke Kampung Tematik Gajahmungkur, mengumpulkan informasi terkait permasalahan yang dan kebutuhan yang saat ini diperlukan adalah membuat desain kemasan produk makanan dan Iklan digital yang menarik dengan menggerakkan pemuda karang taruna Kampung Tematik Gajahmungkur.

2. Melakukan koordinasi kepada ketua karang taruna Kampung Tematik Gajahmungkur, Muhammad Fachtul Amin, S.Sos.I, bersama koordinator program kegiatan pengabdian untuk memastikan jumlah peserta yang akan mengikuti pelatihan dari program pengabdian.

3. Menentukan waktu dan tempat penyelenggaraan

4. Menentukan instruktur. Penentuan instruktur yang akan melaksanakan kegiatan pengabdian masyarakat yakni orang yang berkompeten di bidang desain dan periklanan. Hal tersebut akan dilakukan oleh dosen yang terlibat sebagai tim pengusul yang sedang ditugaskan untuk melakukan pengabdian

5. Membuat undangan bagi mitra. Undangan hadir memberikan informasi tempat dan waktu pelaksanaan kegiatan serta agenda kegiatan.

6. Menyiapkan sarana dan prasarana kegiatan sesuai dengan materi yang akan diajarkan.

7. Pada pelaksanaan pelatihan, terlebih dahulu instruktur menyampaikan materi tentang Iklan Digital, Desain kemasan produk makanan dan tahapan pembuatannya. Instruktur 
mendemonstrasikan pembuatan desain kemasan dengan sarana prasana yang sudah disiapkan. Tahapan selanjutnya, peserta diminta untuk mengikuti demonstrasi yang sebelumnya sudah dilakukan instruktur.

8. Melakukan pengarsipan kegiatan dan pengarsipan laporan berupa undangan peserta, dokumen surat, dokumentasi, daftar hadir dan pembuatan laporan.

9. Mempersiapkan tim konsultasi untuk mendiskusikan permasalahan yang ada dan menghasilkan solusi dari permasalahan tersebut

\subsection{Jadwal Pelaksanaan Kegiatan}

Kegiatan pengabdian ini akan dilaksanakan dengan jadwal dan rincian kegiatan sebagai berikut:

\begin{tabular}{|c|c|c|c|c|c|c|c|c|c|c|c|c|c|}
\hline \multirow[t]{2}{*}{ NO } & \multirow[t]{2}{*}{ KEGIATAN } & \multicolumn{4}{|c|}{$\begin{array}{c}\text { BULAN I } \\
\text { MEI }\end{array}$} & \multicolumn{4}{|c|}{$\begin{array}{l}\text { BULAN } 2 \\
\text { JUNI }\end{array}$} & \multicolumn{4}{|c|}{$\begin{array}{l}\text { BULAN } 3 \\
\text { JULI }\end{array}$} \\
\hline & & 1 & 2 & 3 & 4 & 1 & 2 & 3 & 4 & 1 & 2 & 3 & 4 \\
\hline 1 & Persiapan & & & & & & & & & & & & \\
\hline & $\begin{array}{l}\text { Koordinasi tim pelaksana } \\
\text { dengan mitra }\end{array}$ & & & & & & & & & & & & \\
\hline & $\begin{array}{l}\text { Membuat administrasi } \\
\text { kegiatan }\end{array}$ & & & & & & & & & & & & \\
\hline & $\begin{array}{l}\text { Undangan kegiatan } \\
\text { peserta }\end{array}$ & & & & & & & & & & & & \\
\hline & Membuat materi & & & & & & & & & & & & \\
\hline 2 & Pelaksanaan & & & & & & & & & & & & \\
\hline 3 & Evaluasi & & & & & & & & & & & & \\
\hline 4 & $\begin{array}{l}\text { Evaluasi tim pelaksana } \\
\text { dengan mitra }\end{array}$ & & & & & & & & & & & & \\
\hline 5 & Laporan Kemajuan & & & & & & & & & & & & \\
\hline 6 & Laporan Akhir & & & & & & & & & & & & \\
\hline
\end{tabular}

Rangkaian kegiatan pengabdian masyarakat di Kelurahan Jajan Pasar Gajah Mungkur, Semarang:

\begin{tabular}{|c|c|c|c|}
\hline \multirow[t]{2}{*}{ NO } & \multirow[t]{2}{*}{ LANGKAH } & \multicolumn{2}{|c|}{ PERSIAPAN } \\
\hline & & TUJUAN & HASIL \\
\hline 1 & $\begin{array}{l}\text { Koordinasi tim pelaksana } \\
\text { dengan mitra }\end{array}$ & $\begin{array}{l}\text { Pembahasan agenda } \\
\text { kegiatan iklan digital }\end{array}$ & $\begin{array}{l}\text { Jadwal pelaksanaan } \\
\text { kegiatan }\end{array}$ \\
\hline 2 & Membuat administrasi kegiatan & $\begin{array}{l}\text { Persiapan administrasi } \\
\text { pelaksanaan kegiatan }\end{array}$ & $\begin{array}{l}\text { Surat tugas pelaksanaan } \\
\text { kegiatan pelatihan } \\
\text { desain produk dan iklan } \\
\text { digital }\end{array}$ \\
\hline 3 & Undangan kegiatan peserta & $\begin{array}{l}\text { Pemberitahuan kepada } \\
\text { peserta kegiatan }\end{array}$ & $\begin{array}{l}\text { Peserta mengetahui } \\
\text { jadwal dan waktu } \\
\text { kegiatan }\end{array}$ \\
\hline 4 & Membuat materi kegiatan & $\begin{array}{l}\text { Pembuatan materi kegiatan } \\
\text { yang akan disampaikan ke } \\
\text { peserta }\end{array}$ & $\begin{array}{l}\text { Materi kegiatan yang } \\
\text { disampaikan berupa } \\
\text { modul tentang desain } \\
\text { produk dan iklan digital }\end{array}$ \\
\hline
\end{tabular}




\section{HASIL DAN PEMBAHASAN}

Hasil pelatihan desain produk dan iklan digital, masing- masing peserta harus melakukan kegiatan membuat desain produk yang menarik. Sebelum latihan dimulai, tim menjelaskan ketentuan iklan digital dan desain produk serta tema yang akan diangkat

Kegiatan pengabdian ini berdasarkan permasalahan warga kelurahan Gajahmungkur yang mempunyai usaha di bidang jajan pasar, warga Kelurahan Gajahmungkur membutuhkan pelatihan yang berhubungan dengan desain kemasan produk jajan pasar, karena selama ini desain kemasan yang mereka gunakan kurang menarik perhatian konsumen, sehingga warga meminta untuk mengadakan pelatihan tentang desain kemasan produk makanan dan iklan digital dengan menggerakkan pemuda karang taruna, yang berkoordinasi dengan ketua karang taruna yaitu Muhammad Fachtul Amin, S.Sos

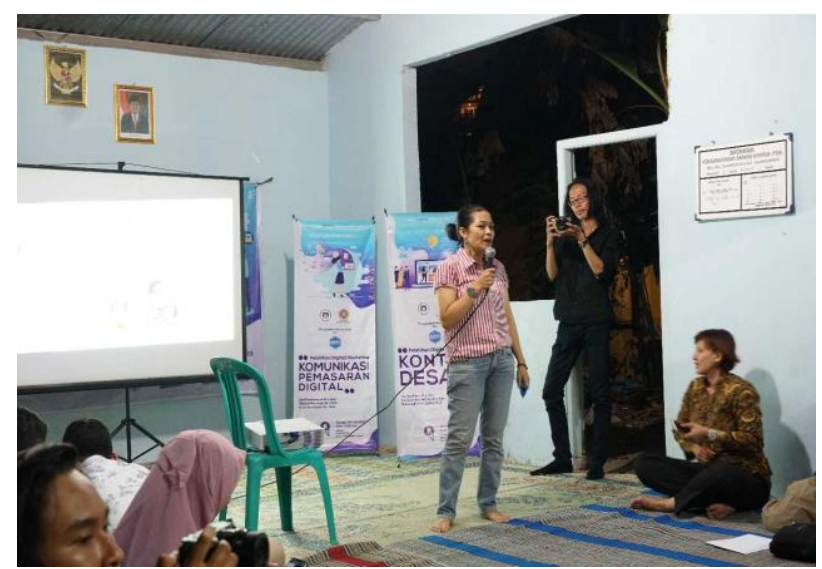

Gambar 1 : penjelasan tentang iklan dan pemasaran digital

Selain desain kemasan, kegiatan ini juga memberi pengetahuan kepada warga kelurahan Gajahmungkur tentang pentingnya iklan digital, karena produk jajan pasar mereka kurang dipromosikan secara digital. Pemasaran secara digital dapat membantu meningkatkan pendapatan warga kampung Kelurahan Gajahmungkur, serta membantu dalam mempromosikan usaha jajan pasar mereka. zaman sekarang ini semua orang mempunyai smartphone yang terhubung ke internet, dan mereka lebih sering berinteraksi dengan smartphone mereka dibandingkan dengan interaksi ke media yang lain. Iklan digital menjadi hal yang menunjang bisnis jajan pasar yang ditekuni oleh warga kampung Gajahmungkur.

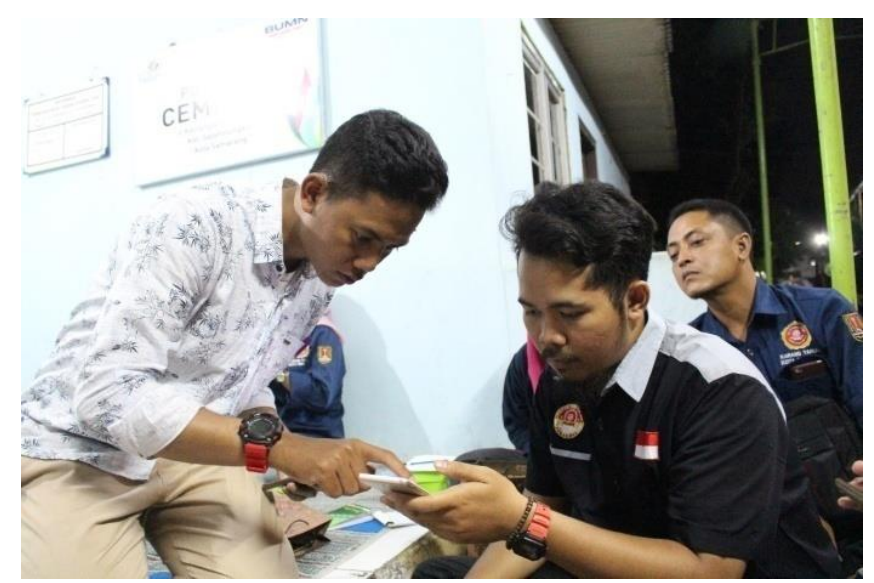

Gambar 2 : peserta mencoba membuat desain produk dengan menggunakan aplikasi Android 


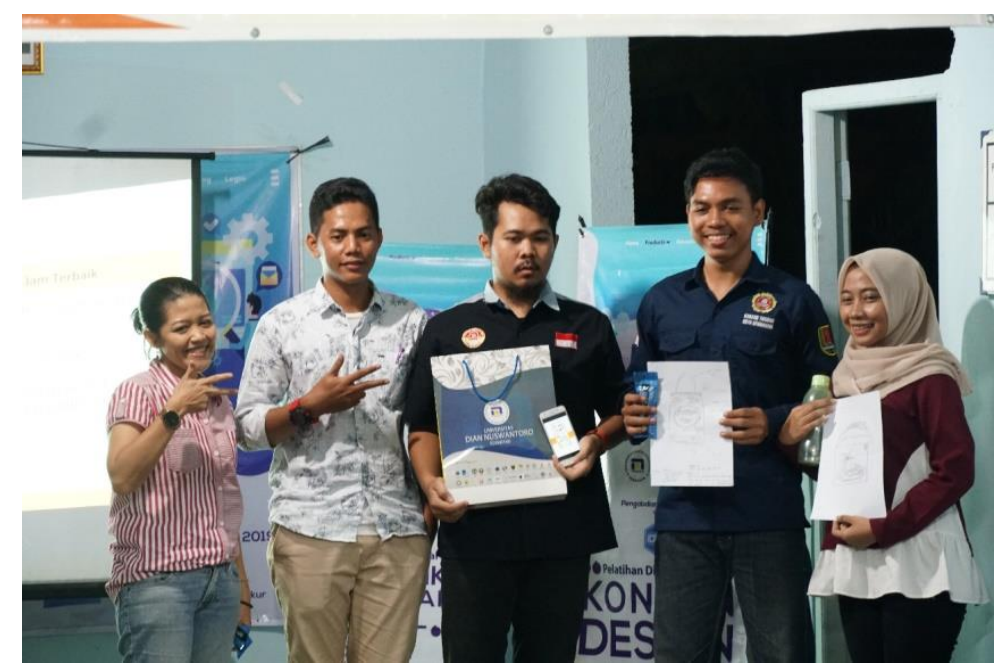

Gambar 3 : penghargaan desain terbaik

Dosen-dosen Udinus membantu mereka dengan mengadakan pengabdian tentang desain kemasan dan pemasaran secara digital, dengan menggunakan program yang bisa di download untuk desan kemasan, serta mengajarkan tentang digital marketing sebagai sarana pemasaran produk. Peserta pengabdian juga praktek secara lengsung dengan menggunakan program tersebut. Tahapan pembuatan kemasan produk tersebut yaitu dimulai dari desain kemasan, dengan menggunakan program canva untuk membantu dalam pembuatan desain tersebut. Instruktur mendemonstrasikan pembuatan desain kemasan dengan sarana prasana yang sudah disiapkan. Tahapan selanjutnya, peserta diminta untuk mengikuti demonstrasi yang sebelumnya sudah dilakukan instruktur. Kegiatan pengabdian ini diakhiri dengan penghargaan desain terbaik

\section{KESIMPULAN DAN SARAN}

Kesimpulan dan saran dari pelatihan yang dilakukan oleh beberapa Dosen Ilmu Komunikasi untuk Karang Taruna Kelurahan Gajahmungkur Semarang adalah:

\section{Kesimpulan}

Pengetahuan peserta yang sebagian besar adalah Karang Taruna warga kelurahan Gajahmungkur makin berkembang, terutama pada pengetahuan tentang pemasaran dan iklan digital serta desain kemasan produk makanan jajan pasar

Peserta pelatihan mengerti tentang strategi pemasaran dan iklan digital, serta pengetahuan tentang desain kemasan dengan menggunakan program Canva

Peningkatan Softskill dalam pembuatan desain kemasan dengan menggunakan program Canva, dapat langsung diaplikasikan ke dalam kemasan produk makanan jajan pasar yang menjadi bisnis warga kampung tematik Gajahmungkur

\section{Saran}

Pelatihan yang diberikan untuk Karang Taruna Kelurahan Gajahmungkur diharapkan mampu menjadi pilot project, sehingga dapat dilakukan secara berkelanjutan dan tidak hanya untuk Kelurahan Gajahmungkur, melainkan merata pada setiap karang taruna kelurahan yang memiliki kampung tematik di daerahnya. Bahkan tidak menutup kemungkinan anggota karang taruna kelurahan Gajahmungkur meneruskan pengetahuan yang telah dimiliki dari pengabdian masyarakat yang telah dilakukan secara berkesinambungan dan berkelanjutan. 


\section{DAFTAR PUSTAKA}

[1] Wirya, Iwan. 1999, Kemasan yang Menjual : Menang Bersaing Melalui Kemasan. Jakarta : PT. Gramedia Pustaka Utama.

[2] Kotler, P and Keller, K.L. 2012. Marketing Management 13 New Jersey: Pearson Prentice Hall, Inc.

[3] Kotler, P. 2012. Manajemen Pemasaran di Indonesia :Analisis,. Perencanaan, Implementasi dan Pengendalian.Jakarta : Penerbit Salemba.

[4] Kurtz , D. L. 2011. Principles of contemporary Marketing 14 th edition. Stamford: South Western Educational Publishing

[5] Basu, S,. \& Irawan, H. 2012. Manajemen Pemasaran Modern Edisi ke-2. Yogyakarta: Liberty Offset 
Abdimasku Jurnal

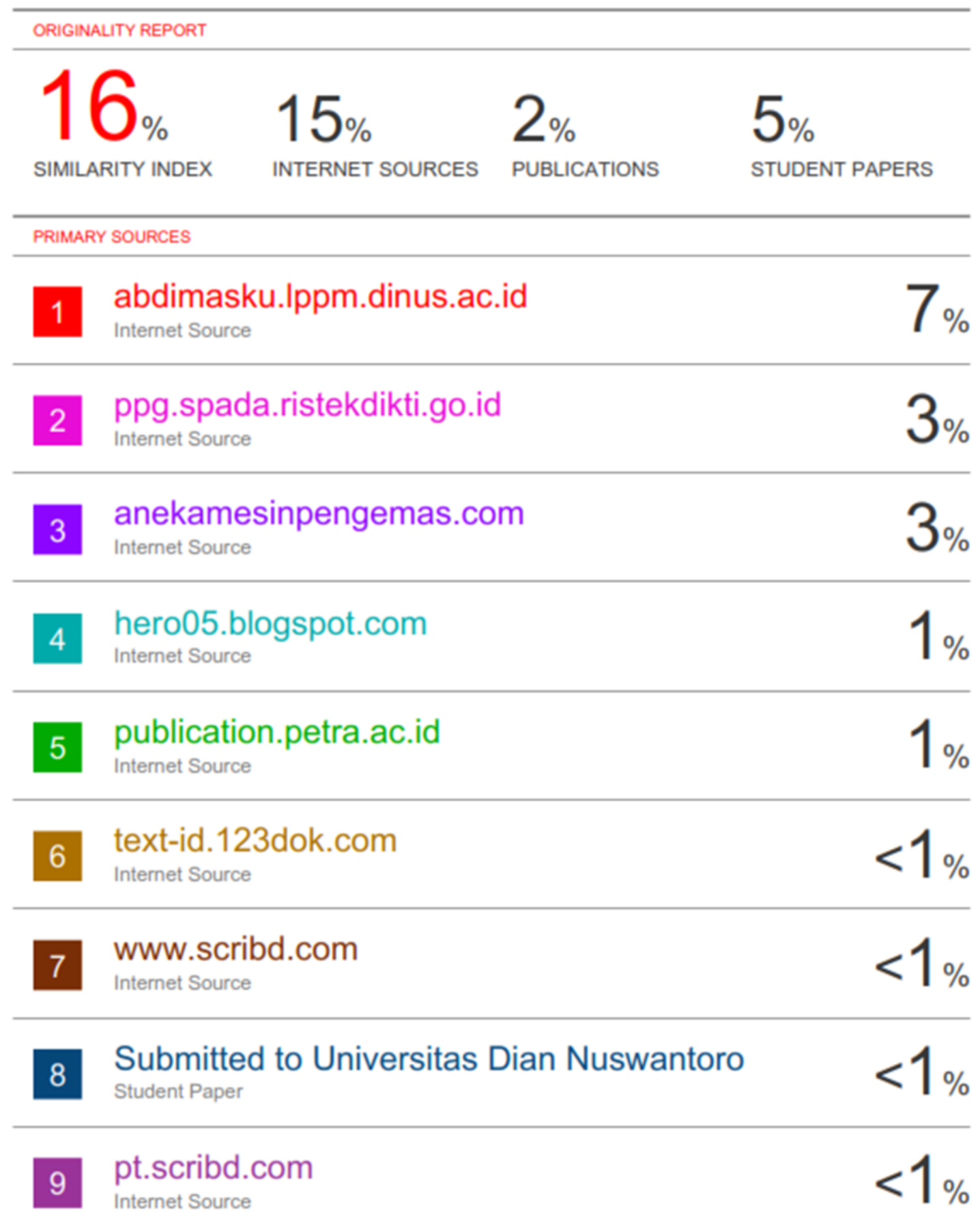


10 suarezhernandezmariel.blogspot.com

Internet Source

11 Agus Setiawan. "TANDA VISUAL SURYA MAJAPAHIT DALAM RELIEF MASJID SEBAGAI KONSEP KOMUNIKASI VISUAL (Studi Kasus Relief Masjid Mantingan, Jepara, Jawa Tengah)", Naditira Widya, 2017 Publication 